\title{
1,4-Cis Selectivity and Molecular Weight Control of Polymer in the Polymerization of 1,3-Butadiene with Metallosalen Complexes/Methylaluminoxane Catalysts
}

\author{
Kiyoshi ENDO* and Takahiro KITAGAwA \\ Department of Bio-Applied and Applied Chemistry, Graduate School of Engineering, Osaka City University, \\ Sugimoto, Sumiyoshi-ku, Osaka 558-8585, Japan \\ * Corresponding author: endo@a-chem.eng.osaka-cu.ac.jp \\ Received January 15, 2005; Accepted April 17, 2005 \\ (c) 2005 The Society of Rubber Industry, Japan
}

\begin{abstract}
Cis-selective and molecular weight control of the polymer in the polymerization of butadiene (Bd) with various metallosalen $\left[\right.$ metal $=\mathrm{Co}, \mathrm{Ni}, \mathrm{Fe}, \mathrm{V}, \mathrm{Ti}$; salen $=N, N^{\prime}$-bis(salicylidene)ethylenediamine] in combination with methylaluminoxane (MAO) was investigated. The activity for the polymerization of Bd was influenced by both substituents of the salen ligands and mixing order of reagents. The activity for the polymerization of $\mathrm{Bd}$ with metallosalen complexes activated by MAO in the presence of $\mathrm{Bd}$ was higher than that in the absence of $\mathrm{Bd}$. By introducing the tert-butyl group in the aromatic ring of salen, the activity for the polymerization of $\mathrm{Bd}$ increased, but the microstructure of the poly(Bd) did not change significantly. Among the metallosalen complexes examined, $N, N^{\prime}$-bis $(3,5$ di-tert-butylsalicylidene)ethylenediaminato $\mathrm{Co}(\mathrm{II})$ (1-Co) complex in combination with MAO gave the high molecular weight polymer with highest 1,4-cis content. Molecular weight control of the polymer was achieved by the polymerization of $\mathrm{Bd}$ with 1-Co/MAO catalyst.
\end{abstract}

Keywords Butadiene, Polymerization, High 1,4-cis, Metallosalen complexes, $N, N^{\prime}$-bis(3,5-di-tert-butylsalicylidene)ethylenediaminato cobalt(II), Molecular weight control.

\section{Introduction}

Butadiene $(\mathrm{Bd})$ is an important monomer used as a basic chemical of synthetic rubbers such as butadiene rubber (BR) and styrene-butadiene rubber (SBR) which are important polymers for rubber industry. Poly $(\mathrm{Bd})$ has four kinds of microstructures; 1,4-cis, 1,4-trans, 1,2syndiotactic, 1,2-isotactic, and physical and mechanical properties of the polymer depend strongly on the microstructures ${ }^{1)}$. Namely, 1,2-syndiotactic poly(Bd) is crystalline resin, and the melting point of the polymer changes from 70 to $216^{\circ} \mathrm{C}$ according to a difference in crystallinity. 1,4-Trans polymer is also resin which melts at $100-141^{\circ} \mathrm{C}$. $1,4-C i s$ poly $(\mathrm{Bd})$ has rubber elasticity, and high 1,4-cis poly $(\mathrm{Bd})$ is used for tire material, and low 1,4cis poly $(\mathrm{Bd})$ is utilized as a modifier for impact absorber of polyethylene. The materials having good physical and mechanical properties can be obtained by choosing adequate catalysts through precisely controlled polymerization of $\mathrm{Bd}$.

Metallocene catalysts make it possible to control of stereoregularity of polymer by designing ligands of catalysts $^{2}$. Moreover, homogeneous post-metallocene catalysts such as $\mathrm{Ni}(\mathrm{ii})$ di-imine complexes ${ }^{3,4)}$, Ti(IV) diamide complexes ${ }^{5)}$, and $\mathrm{Ni}(\mathrm{II})$ imin-pyridine complexes ${ }^{6,7)}$ have been discovered, in which they show a high activity for polymerization of olefin and other monomers.

On the other hand, high 1,4-cis polymerization of butadiene $(\mathrm{Bd})$ with Ziegler-Natta catalysts such as $\left.\mathrm{TiI}_{4} / \mathrm{AlR}_{3}{ }^{8}\right), \quad \mathrm{CoCl}_{2} \cdot(\text { pyridine })_{2} / \mathrm{AlEt}_{2} \mathrm{Cl}^{9)}, \quad\left(\eta^{3}-\mathrm{C}_{3} \mathrm{H}_{5}\right) \mathrm{Ni}-$ $\left(\mathrm{OCOCF}_{3}\right)^{10)}$, and $\mathrm{Nd}(\text { carboxylate })_{3} / \mathrm{AlEt}_{2} \mathrm{Cl} / \mathrm{Al}(i-\mathrm{Bu})_{3}{ }^{11)}$ have been reported. Metallocene complexes in combination with methylaluminoxane (MAO) are also effective catalysts for producing a high 1,4-cis polymer in the polymerization of 1,3-dienes. Such examples were found in the polymerization with $\mathrm{CpTiCl}_{3}{ }^{12)}$, $\mathrm{CpVCl}_{2}\left(\mathrm{PEt}_{3}\right)_{2}$ and $\left.\mathrm{Cp}_{2} \mathrm{VCl}^{13}\right)$ to give the polymers consisting of mainly 1,4 -cis units.

Among many transition metal complexes, metallosalen complexes are known to be useful as catalysts for an asymmetric epoxidation ${ }^{14)}$. However, some of them have been utilized as polymerization catalysts in an 
oligomerization of ethylene with zirconium-salen complex ${ }^{15)}$, a polymerization of norbornene with nickelsalen complex/MAO ${ }^{16)}$, and a polymerization of propylene with $\mathrm{MgCl}_{2}$-supported 1,2-cyclohexanediamino- $N, N^{\prime}$ bis(3,5-di-tert-butylsalicylidene)manganese chloride activated by $\mathrm{AlEt}_{2} \mathrm{Cl}$ to give an atactic polymer with a high molecular weight ${ }^{17)}$. However, there are few reports on polymerizations of 1,3-dienes with metallosalen complexes. An example is found in the literature for the polymerization of $\mathrm{Bd}$ with 1,2-cyclohexanediamino- $N, N^{\prime}$ bis(3,5-di-tert-butyl-salicylidene) $\mathrm{Ni} / \mathrm{BF}_{3} \mathrm{OBu}_{2} / \mathrm{MAO}$ catalyst to give 1,4 -cis poly $(\mathrm{Bd})^{18)}$. These results suggests that various metallosalen complexes are capable of effective catalysts for the polymerization of $\mathrm{Bd}$ to produce high 1,4-cis polymer by designing the ligand of salen, although detailed study for the polymerization of $\mathrm{Bd}$ with metallosalen complexes in combination with MAO has not been investigated.

In this article, we report on the polymerization of $\mathrm{Bd}$ with metallosalen complexes. Moreover, the molecular weight control of the polymer will be described in the polymerization of $\mathrm{Bd}$ with $N, N^{\prime}$-bis(3,5-di-tertbutylsalicylidene)ethylenediaminato $\mathrm{Co}(\mathrm{II})$ (1-Co)/MAO catalysts.

\section{Experimental}

\section{Materials}

Bd was purified by distillation over calcium hydride before use. Commercially available $\mathrm{Ni}(\mathrm{II})$ (salen) and $\mathrm{Co}(\mathrm{II})$ (salen) were used as received. MAO diluted with toluene kindly supplied from Tosoh Co. was used as received. Solvents were used after purification by conventional methods. Other chemicals were obtained commercially and used as received.

\section{$N, N^{\prime}$-Bis(3,5-di-tert-butylsalicylidene)ethylenediamine (1)}

To a solution of 3,5-di-tert-butylsalicylaldehyde (1.5 g, $6.4 \mathrm{mmol})$ in methanol $(50 \mathrm{ml})$ was added ethylenediamine $(0.192 \mathrm{~g}, 3.2 \mathrm{mmol})$. The mixture was stirred at room temperature for $2 \mathrm{~h}$ and then filtered off. After filtration the light-yellow powder was washed with a small amount of cold hexane and dried under vacuum to give $1.33 \mathrm{~g}$ $(78.5 \%)$ of $\quad N, N^{\prime}$-Bis(3,5-di-tert-butylsalicylidene)ethylenediamine (1). mp $188-189^{\circ} \mathrm{C} .{ }^{1} \mathrm{H} \mathrm{NMR}\left(\mathrm{CDCl}_{3}\right)$ : d $13.64(1 \mathrm{H}, \mathrm{OH}), 8.38(1 \mathrm{H}, \mathrm{ArCH}=\mathrm{N}), 7.35(1 \mathrm{H}, \mathrm{ArH})$, $7.25(1 \mathrm{H}, \mathrm{ArH}), 3.91\left(2 \mathrm{H}, \mathrm{CH}_{2} \mathrm{~N}\right), 1.42(9 \mathrm{H}, t-\mathrm{Bu}-M e)$, $1.27\left(9 \mathrm{H}, t\right.$-Bu-Me). IR (KBr) $3422\left(v_{\mathrm{O}-\mathrm{H}}\right), 1628\left(v_{\mathrm{C}=\mathrm{N}}\right)$ $\mathrm{cm}^{-1}$.
$N, N^{\prime}$-Bis(3,5-di-tert-butylsalicylidene)ethylenediaminato nickel(II) (1-Ni)

To a solution of $\mathbf{1}(1.2 \mathrm{~g}, 2.4 \mathrm{mmol})$ was added $\mathrm{Ni}(\mathrm{OAc})_{2} \cdot 4 \mathrm{H}_{2} \mathrm{O}(0.607 \mathrm{~g}, 2.4 \mathrm{mmol})$. The mixture was refluxed for $2 \mathrm{~h}$ and then filtered off. After filtration the dark yellow needles was washed with a small amount of cold methanol and dried under vacuum to give $1.31 \mathrm{~g}$ $(72.7 \%)$ of 1 -Ni. ${ }^{1} \mathrm{H}$ NMR $\left(\mathrm{CDCl}_{3}\right):$ d $7.49 \quad(1 \mathrm{H}$, $\mathrm{ArCH}=\mathrm{N}), 7.30(1 \mathrm{H}, \mathrm{ArH}), 6.87(1 \mathrm{H}, \mathrm{ArH}), 3.30(2 \mathrm{H}$, $\left.\mathrm{CH}_{2} \mathrm{~N}\right), 1.16(9 \mathrm{H}, t-\mathrm{Bu}-\mathrm{Me})$. IR (KBr) $1621\left(v_{\mathrm{C}=\mathrm{N}}\right) \mathrm{cm}^{-1}$.

\section{N,N'-Bis(3,5-di-tert-butylsalicylidene)ethylenediaminato cobalt(II) (1-Co)}

$N, N^{\prime}$-Bis(3,5-di-tert-butylsalicylidene)ethylenediaminato cobalt(II) (1-Co) was prepared from an equimolar amount of 1 and $\mathrm{Co}(\mathrm{OAc})_{2} \cdot 4 \mathrm{H}_{2} \mathrm{O}$ in a similar manner to that for 1-Ni (orange powder, 71.1\%). ${ }^{1} \mathrm{H} \mathrm{NMR}\left(\mathrm{CDCl}_{3}\right)$ : d $7.51(1 \mathrm{H}, \mathrm{ArCH}=\mathrm{N}), 7.06(1 \mathrm{H}, \mathrm{ArH}), 6.99(1 \mathrm{H}, \mathrm{ArH})$, $3.92\left(2 \mathrm{H}, \mathrm{CH}_{2} \mathrm{~N}\right), 1.43(9 \mathrm{H}, t-\mathrm{Bu}-M e), 1.28(9 \mathrm{H}, t-\mathrm{Bu}-M e)$. IR $(\mathrm{KBr}) 1596\left(v_{\mathrm{C}=\mathrm{N}}\right) \mathrm{cm}^{-1}$.

\section{$N, N^{\prime}$-Bis(3,5-di-tert-butylsalicylidene)ethylenediaminato iron(III) (1-Fe)}

$N, N^{\prime}$-Bis(3,5-di-tert-butylsalicylidene)ethylenediaminato iron(III) (1-Fe) was prepared from an equimolar amount of $\mathbf{1}$ and $\mathrm{FeSO}_{4} \cdot 7 \mathrm{H}_{2} \mathrm{O}$ in a similar manner to that for $\mathbf{1 - N i}$ (dark-purple powder, 67.5\%). ${ }^{1} \mathrm{H}$ NMR $\left(\mathrm{CDCl}_{3}\right)$ : d 8.33 $(1 \mathrm{H}, \mathrm{ArCH}=\mathrm{N}), 7.60(1 \mathrm{H}, \mathrm{ArH}), 7.31(1 \mathrm{H}, \mathrm{ArH}), 4.20$ $\left(2 \mathrm{H}, \mathrm{CH}_{2} \mathrm{~N}\right), 1.51(9 \mathrm{H}, t$-Bu-Me), $1.32(9 \mathrm{H}, t$-Bu-Me). IR $(\mathrm{KBr}) 1621\left(v_{\mathrm{C}=\mathrm{N}}\right) \mathrm{cm}^{-1}$.

\section{N,N'-Bis(3,5-di-tert-butylsalicylidene)ethylenediaminato titanium(IV) dichloride (1-Ti)}

$N, N^{\prime}$-Bis(3,5-di-tert-butylsalicylidene)ethylenediaminato titanium dichloride (1-Ti) was prepared from an equimolar amount of $\mathbf{1}$ and $\mathrm{TiCl}_{4}$ in a similar manner to that for $\mathbf{1 - N i}$ under nitrogen atmosphere (red powder, 49.3\%). ${ }^{1} \mathrm{H}$ NMR $\left(\mathrm{CDCl}_{3}\right)$ : d $7.74(1 \mathrm{H}, \mathrm{ArCH}=\mathrm{N}), 7.52(1 \mathrm{H}, \mathrm{ArH}), 7.00$ $(1 \mathrm{H}, \mathrm{ArH}), 3.92\left(2 \mathrm{H}, \mathrm{CH}_{2} \mathrm{~N}\right), 1.53(9 \mathrm{H}, t-\mathrm{Bu}-M e), 1.36$ (9H, $t$-Bu-Me). IR (KBr) $1617\left(v_{\mathrm{C}=\mathrm{N}}\right) \mathrm{cm}^{-1}$.

\section{N,N'-Bis(3,5-di-tert-butylsalicylidene)ethylenediaminato vanadium(III) chloride (1-V)}

$N, N^{\prime}$-Bis(3,5-di-tert-butylsalicylidene)ethylenediaminato vanadium chloride (1-V) was prepared by the reaction of $\mathbf{1}$ and $\mathrm{VCl}_{3}$ in a similar manner to that for $\mathbf{1 - N i}$ (red powder, 49.3\%). ${ }^{1} \mathrm{H}$ NMR $\left(\mathrm{CDCl}_{3}\right): \mathrm{d} 7.49(1 \mathrm{H}, \mathrm{ArCH}=\mathrm{N}), 7.30$ $(1 \mathrm{H}, \mathrm{ArH}), 6.87(1 \mathrm{H}, \mathrm{ArH}), 3.30\left(2 \mathrm{H}, \mathrm{CH}_{2} \mathrm{~N}\right), 1.40(9 \mathrm{H}, t-$ $\mathrm{Bu}-M e), 1.25(9 \mathrm{H}, t-\mathrm{Bu}-\mathrm{Me})$. IR $(\mathrm{KBr}) 1617\left(v_{\mathrm{C}=\mathrm{N}}\right) \mathrm{cm}^{-1}$. 


\section{Polymerization procedure}

Polymerization was carried out in a sealed glass tube with a rubber septum with a connection to a vacuum system. After purging the tube with nitrogen, $8 \mathrm{ml}$ of $\mathrm{CH}_{2} \mathrm{Cl}_{2}$ solution of complex, $1 \mathrm{ml}$ of $\mathrm{Bd}$ and $1 \mathrm{ml}$ of MAO solution was charged into the tube in this order. $\mathrm{Bd}$ monomer was charged at $-78^{\circ} \mathrm{C}$ by a vacuum distillation over calcium hydride. Then the tube was sealed under high vacuum. The polymerization was carried out in a thermostat at a constant temperature for a given time. After polymerization, the tube was opened, and the contents of the tube were poured into a $200 \mathrm{ml}$ of methanol containing a small amount of hydrochloric acid and p-tertbutylphenol to precipitate the polymer formed. The polymers was washed with methanol and dried in vacuo. Polymer yield was calculated by gravimetry.

\section{Characterization of polymers}

Number average molecular weight $\left(M_{n}\right)$ and weight average molecular weight $\left(M_{w}\right)$ and molecular weight distribution $\left(M_{w} / M_{n}\right)$ of the polymer were estimated by gel permeation chromatography (GPC) using a Tosoh 8000 series system in tetrahydrofuran as calibrated with polystyrene standards. The microstructure of poly $(\mathrm{Bd})$ was determined from ${ }^{1} \mathrm{H}$ and ${ }^{13} \mathrm{C}$ NMR spectra taken in $d$ chloroform solvent at $20^{\circ} \mathrm{C}$ on a JEOL $\alpha$-400NMR spectrometer.

\section{Results and Discussion}

\section{Polymerization of $\mathrm{Bd}$ with metallosalen/MAO catalyst}

In the polymerization of $\mathrm{Bd}$ with transition metal complexes, ligands of the metal complexes play a role to determine both activities for polymerization and 1,4-cis content. ${ }^{1)}$ For this purpose, late transition metal complexes bearing the salen ligand introduced tert-butyl group in the aromatic ring of salen were synthesized, i.e., $N, N^{\prime}$-bis(3,5di-tert-butylsalicylidene)ethylenediaminato nickel(II) (1Ni) and $N, N^{\prime}$-bis (3,5-di-tert-butylsalicylidene)ethylenediaminato cobalt(II) (1-Co) as shown in Figure 1 was synthesized and compared with (salen)Ni(II) and (salen)Co(II), in which the metallosalen complexes were activated with MAO in the absence of $\mathrm{Bd}$. The polymerization of $\mathrm{Bd}$ with these complexes in combination with MAO was conducted. The results are listed in Table 1. In a preliminary experiment, polymerization of $\mathrm{Bd}$ was tested. The polymerization proceeded smoothly in $\mathrm{CH}_{2} \mathrm{Cl}_{2}$, but the polymerization did not gave almost no polymer in toluene. This may be explained by that (salen) $\mathrm{Ni}$ (II) is soluble in $\mathrm{CH}_{2} \mathrm{Cl}_{2}$, but insoluble in toluene. Thus, $\mathrm{CH}_{2} \mathrm{Cl}_{2}$ was used as the polymerization solvent in this study. The activity for polymerization of $\mathrm{Bd}$ with (salen) $\mathrm{Ni}(\mathrm{II})$ and (salen)Co(II) complexes bearing ligand $\mathbf{1}$ introduced tertbutyl group was higher than that with (salen) Ni(II)/MAO and (salen) $\mathrm{Co}(\mathrm{II}) / \mathrm{MAO}$ catalysts.

\section{Effect of mixing order of the reagents}

A mixing order of the reagents was reported to play an important role to determine the activity for polymerization of $\mathrm{Bd}$ with binary catalysts ${ }^{1)}$. In the polymerization of $\mathrm{Bd}$ with $\mathrm{V}(\mathrm{acac})_{3} / \mathrm{MAO}$ catalyst, the microstructure of polymer and the activity for the polymerization was reported to depend strongly on a mixing order of reagents including $\mathrm{Bd}$ monomer ${ }^{13,19)}$. Moreover, in the polymerization of $\mathrm{Bd}$ with $\mathrm{Co}(\mathrm{acac})_{3} / \mathrm{MAO}$ catalyst, the rate of polymerization increased with an addition of MAO to Co complex in the presence of $\mathrm{Bd}^{20-22)}$. To check this point in the polymerization of $\mathrm{Bd}$ with 1-Co/MAO or 1$\mathrm{Ni} / \mathrm{MAO}$ catalyst, the various mixing order of metallosalen

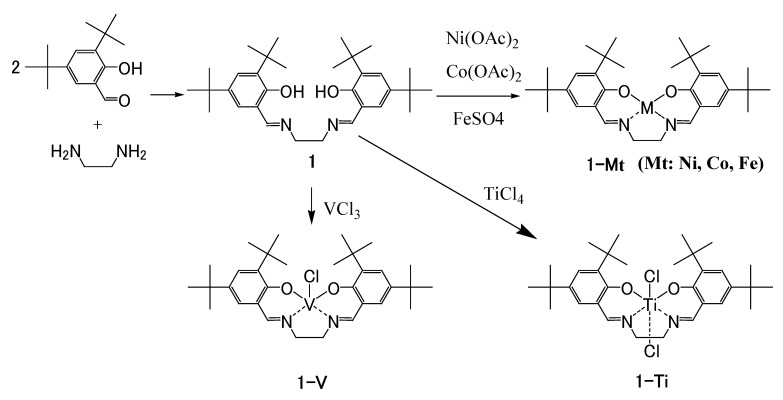

Figure 1. Synthesis of the metallosalen complexes.

Table 1. Polymerization of Bd with metallosalen/MAO catalyst in $\mathrm{CH}_{2} \mathrm{Cl}_{2}$ at $20^{\circ} \mathrm{C}$

\begin{tabular}{|c|c|c|c|c|c|c|c|}
\hline \multirow{2}{*}{ Metallosalen } & \multirow{2}{*}{ Time (h) } & \multirow{2}{*}{$\begin{array}{c}\text { Polymer yield } \\
(\%)\end{array}$} & \multirow{2}{*}{$M_{n} \times 10^{-4}$} & \multirow{2}{*}{$M_{w} / M_{n}$} & \multicolumn{3}{|c|}{ Microstructure (\%) } \\
\hline & & & & & $1,4-c i s$ & 1,4-trans & 1,2-vinyl \\
\hline $\mathrm{Ni}$ (salen) & 16 & 43.8 & 2.3 & 2 & 85 & 9.7 & 5.3 \\
\hline $1-\mathrm{Ni}$ & 1 & 79.5 & 2.2 & 3 & 92.3 & 4.1 & 3.6 \\
\hline Co(salen) & 3 & 8.9 & 2.9 & 2 & 92.5 & 4.3 & 3.2 \\
\hline $\mathrm{Co}$ (salen) & 24 & 34.9 & 2.7 & 3.6 & 91.8 & 4.8 & 3.4 \\
\hline 1-Co & 12 & 31.2 & 4.7 & 3.3 & 96.6 & $\sim 0$ & 3.4 \\
\hline
\end{tabular}

$[\mathrm{Bd}]=1.2 \mathrm{~mol} / \mathrm{L},[\mathrm{Metal}]=6.7 \times 10^{-4} \mathrm{~mol} / \mathrm{L}, \mathrm{MAO} / \mathrm{Metal}=500 \mathrm{~mole}$ ratio. 
Table 2. Effect of mixing order of the reagents on polymerization of $\mathrm{Bd}$ with metallosalen/MAO catalyst in $\mathrm{CH}_{2} \mathrm{Cl}_{2}$ at $20^{\circ} \mathrm{C}$

\begin{tabular}{|c|c|c|c|c|c|c|c|}
\hline \multirow{2}{*}{ Mixing order } & \multirow{2}{*}{ Time (h) } & \multirow{2}{*}{$\begin{array}{c}\text { Polymer yield } \\
(\%)\end{array}$} & \multirow{2}{*}{$M_{n} \times 10^{-4}$} & \multirow{2}{*}{$M_{w} / M_{n}$} & \multicolumn{3}{|c|}{ Microstructure (\%) } \\
\hline & & & & & 1,4-cis & 1,4-trans & 1,2-vinyl \\
\hline $\mathrm{Ni} \rightarrow \mathrm{MAO} \rightarrow \mathrm{Bd}$ & 1 & 79.5 & 2.2 & 3 & 92.3 & 4.1 & 3.6 \\
\hline $\mathrm{Ni} \rightarrow \mathrm{Bd} \rightarrow \mathrm{MAO}$ & 1 & 81.5 & 1.7 & 2.6 & 93.1 & 4.8 & 2.1 \\
\hline $\mathrm{Co} \rightarrow \mathrm{MAO} \rightarrow \mathrm{Bd}$ & 6 & trace & - & - & - & - & - \\
\hline $\mathrm{Co} \rightarrow \mathrm{Bd} \rightarrow \mathrm{MAO}$ & 0.5 & 81.2 & 8.9 & 3.3 & 96.7 & $\sim 0$ & 3.3 \\
\hline
\end{tabular}

$[\mathrm{Bd}]=1.2 \mathrm{~mol} / \mathrm{L},[\mathrm{Metal}]=6.7 \times 10^{-4} \mathrm{~mol} / \mathrm{L}, \mathrm{MAO} / \mathrm{Metal}=500 \mathrm{~mole}$ ratio.

Table 3. Polymerization of $\mathrm{Bd}$ with metallosalen/MAO catalyst in $\mathrm{CH}_{2} \mathrm{Cl}_{2}$ at $20^{\circ} \mathrm{C}$

\begin{tabular}{|c|c|c|c|c|c|c|c|}
\hline \multirow{2}{*}{$1-M$} & \multirow{2}{*}{ Time (h) } & \multirow{2}{*}{$\begin{array}{l}\text { Polymer yield } \\
(\%)\end{array}$} & \multirow{2}{*}{$M_{n} \times 10^{-4}$} & \multirow{2}{*}{$M_{w} / M_{n}$} & \multicolumn{3}{|c|}{ Microstructure (\%) } \\
\hline & & & & & 1,4 -cis & 1,4-trans & $1,2-$ \\
\hline $1-\mathrm{Ni}$ & 1 & 79.5 & 2.2 & 3 & 92.3 & 4.1 & 3.6 \\
\hline 1-Co & 0.5 & 81.2 & 8.9 & 3.3 & 96.7 & $\sim 0$ & 3.3 \\
\hline 1-Fe & 1 & 17.3 & 7 & 2.7 & 82.2 & 7.3 & 10.5 \\
\hline $1-V$ & 6 & 9.9 & 1.5 & 1.3 & $\sim 0$ & 90.5 & 9.5 \\
\hline $1-\mathrm{Ti}$ & 3 & trace & - & - & - & - & - \\
\hline
\end{tabular}

$[\mathrm{Bd}]=1.2 \mathrm{~mol} / \mathrm{L},[\mathrm{M}]=6.7 \times 10^{-4} \mathrm{~mol} / \mathrm{L}, \mathrm{MAO} / \mathrm{Metal}=500 \mathrm{~mole}$ ratio.

The reagents were charged in order of metal complex, Bd and MAO.

complex, Bd, and MAO was changed. Namely, the metallosalen complex was activated by MAO in the presence or absence of $\mathrm{Bd}$ monomer. The results for $\mathbf{1 -}$ $\mathrm{Ni} / \mathrm{MAO}$ and 1-Co/MAO catalyst systems are shown in Tables 2. Effect of a mixing order of reagents on the activity for polymerization of $\mathrm{Bd}$ with 1-Co/MAO was observed. The activity for the polymerization of $\mathrm{Bd}$ with $\mathbf{1 -}$ $\mathrm{Co} / \mathrm{MAO}$ activated by $\mathrm{MAO}$ in the presence of $\mathrm{Bd}$ monomer was found to be higher than that activated in the absence of $\mathrm{Bd}$. The effect of mixing order of the reagents on the polymerization may be explained by a difference in the stability of the Co complex in the presence and absence of $\mathrm{Bd}$ as illustrated in Figure 2. In the polymerization of $\mathrm{Bd}$ with the catalyst prepared in the presence of $\mathrm{Bd}, \pi$ electrons from the alkenyl group can be donated into the vacant $d$ orbitlal of the $\mathrm{Co}$ atom to stabilize the $\mathrm{Co}-\mathrm{C}$ bond. Alternatively, when the ligand is the alkenyl group, $\pi$-allyl bond can form easily to stabilize the active site for polymerization $^{1)}$. In the absence of $\mathrm{Bd}$ such stabilization may be operated to lead the reduction of zerovalent Co or decomposition of the Co complex ${ }^{1)}$.

On the other hand, the activity for the polymerization of Bd with 1-Ni/MAO catalyst was not affected by the mixing order of the reagents as shown in Table 2 . Although the reason for a difference in the activity for the polymerization of $\mathrm{Bd}$ between 1-Ni and 1-Co is not clear, the stability of $\mathrm{Ni}-\mathrm{C}$ bond may be different from that of Co-C bond.

\section{In the presence of Bd}<smiles>CC1CC(=O)OC1C(=O)OC(C)(C)C</smiles><smiles>C=CC=CC</smiles>

(Stable Complex)

Figure 2. Active site formation of Co complex activated by MAO in the presence of butadiene.

\section{Polymerization of Bd with 1-Metal/MAO catalysts}

In the polymerization of $\mathrm{Bd}$ with transition metal catalysts, it is known that a microstructure of polymer and an activity for the polymerization are strongly dependent on the central metal ${ }^{19-22)}$. To check this point in the polymerization of $\mathrm{Bd}$ with metallosalen/MAO catalysts, some transition metallosalen complexes in addition to $\mathbf{1 - N i}$ and 1-Co complexes were synthesized as shown in Figure 1 , and the polymerization of $\mathrm{Bd}$ with these metallosalen complexes was examined. The results for the polymerization of $\mathrm{Bd}$ with transition metallosalen complexes bearing the same ligand $\mathbf{1}$ in combination with MAO are listed in Table 3. The activity for the polymerization of $\mathrm{Bd}$ was found to depend strongly on the center metal examined. On concerning the central metal, the activity for the polymerization of $\mathrm{Bd}$ decreased with the following order: 1-Co $>\mathbf{1 - N i}>\mathbf{1 - F e}>\mathbf{1 - V}>\mathbf{1 - T i}$. Namely, late transition metallosalene complexes showed a high activity for the polymerization of $\mathrm{Bd}$. The GPC elution curves of polymers obtained with these catalysts 


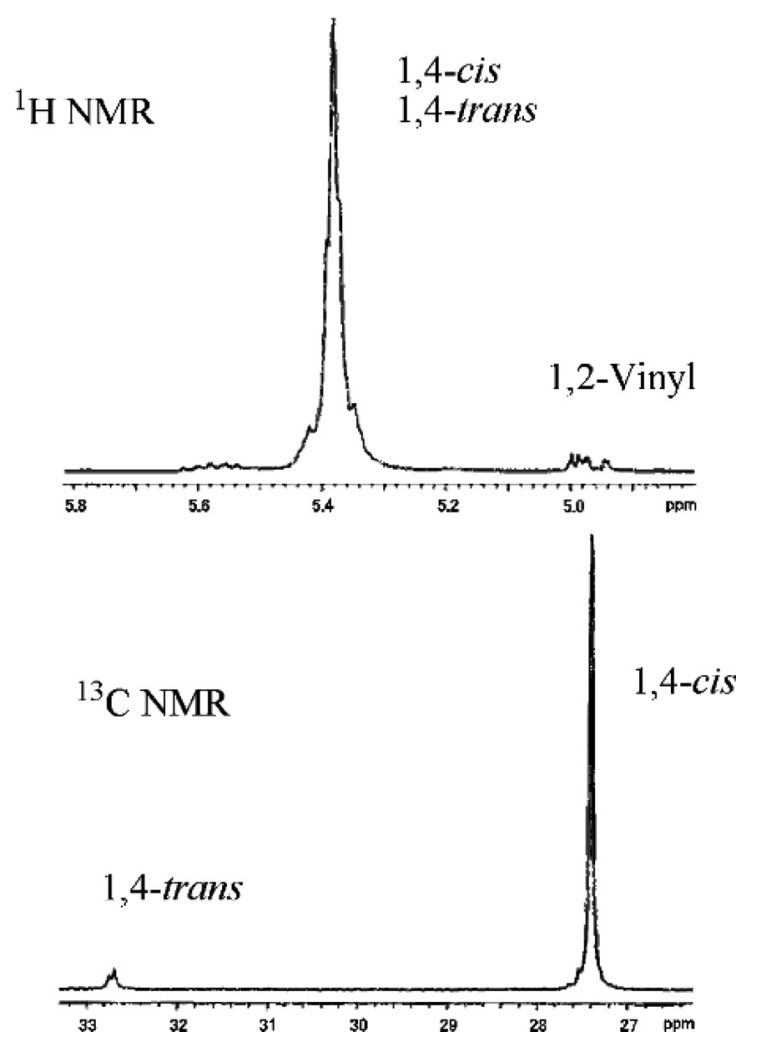

Figure 3. ${ }^{1} \mathrm{H}$ and ${ }^{13} \mathrm{C}$ NMR spectra of poly(butadiene) obtained with 1-Co/MAO catalyst.

were unimodal, suggesting that the polymerization of $\mathrm{Bd}$ proceeds with a single active site.

The microstructure of the polymers obtained from the polymerization of $\mathrm{Bd}$ with metallosalen/MAO catalyst was determined using ${ }^{1} \mathrm{H}$ and ${ }^{13} \mathrm{C}$ NMR spectra of the polymers. The typical ${ }^{1} \mathrm{H}$ and ${ }^{13} \mathrm{C}$ NMR spectra of the polymers are shown in Figure 3. In accordance with the activity for the polymerization, the 1,4-cis content of the polymer obtained with late transition metals was higher than these obtained with early transition metal complexes such as 1Ti/MAO catalyst and 1-V/MAO catalyst, which is in a good agreement with the results reported previously for the polymerization of Bd with metal( $(\mathrm{acac})_{x} / \mathrm{MAO}$ catalysts $^{19)}$.

Since 1-Co/MAO and 1-Ni/MAO gave a polymer with high 1,4-cis content in a good yield, the polymerization of $\mathrm{Bd}$ with these catalysts was investigated in detail. The polymerization of Bd with 1-Metal/MAO (Metal: Ni, Co) catalysts activated by MAO in the presence of $\mathrm{Bd}$ monomer was conducted. The results using (salen)Ni(II)/ MAO catalyst and (salen)Co(II) catalyst are shown in Figures 4 and 5, respectively. The results for the polymerization of (salen)Ni(II)/MAO catalyst and (salen) $\mathrm{Co}(\mathrm{II})$ catalyst are also indicated for comparison. When 1-Ni/MAO and 1-Co/MAO were used as catalysts,

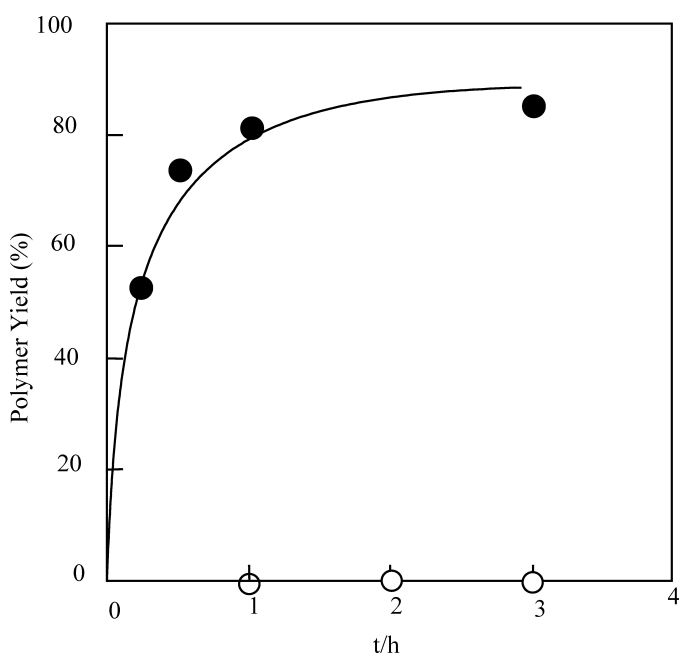

Figure 4. Polymerization of butadiene (Bd) with Ni complex/MAO catalyst in $\mathrm{CH}_{2} \mathrm{Cl}_{2}$ at $20^{\circ} \mathrm{C}$; $[\mathrm{Bd}]=1.2 \mathrm{~mol} / \mathrm{L}$, [Ni] $=6.7 \times 10^{-4} \mathrm{~mol} / \mathrm{L}$, $\mathrm{MAO} / \mathrm{Ni}=500$ mole ratio, $(\bullet) \mathbf{1 - N i},(\bigcirc)$ (salen)Ni(II). The reagents were charged in the order of Ni complex, Bd, and MAO.

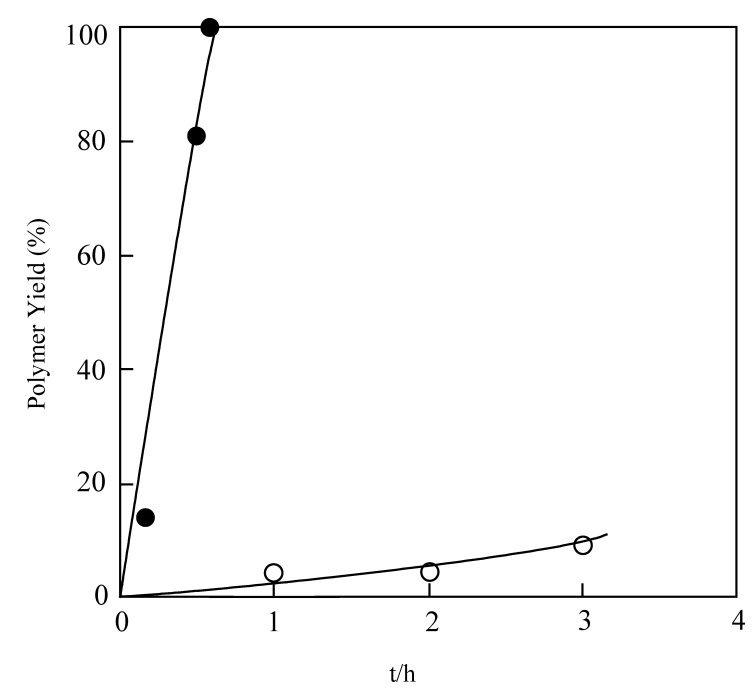

Figure 5. Polymerization of butadiene (Bd) with Co complex/ MAO catalyst in $\mathrm{CH}_{2} \mathrm{Cl}_{2}$ at $20^{\circ} \mathrm{C}$; $[\mathrm{Bd}]=1.2 \mathrm{~mol} / \mathrm{L},[\mathrm{Co}]=6.7 \times 10^{-4}$ $\mathrm{mol} / \mathrm{L}, \mathrm{MAO} / \mathrm{Co}=500$ mole ratio, $(\bullet)$ 1-Co, $(\bigcirc)$ (salen)Co(II). The reagents were charged in the order of Co complex, $\mathrm{Bd}$, and MAO.

the polymerization rates of $\mathrm{Bd}$ with these catalysts were accelerated remarkably as compared with those by the (salen)Ni(II)/MAO catalyst and the (salen)Co(II)/MAO catalyst. This may be explained by the distortion of the coplanarity between the central metal and the liagnds of the salen from the analysis of X-ray powder diffraction pattern of the complexes, which has relation with the formation of an active site by reaction of the lagand and MAO to give a metal-methyl bond. 


\section{Molecular weight control with 1-Co/MAO catalyst}

A simultaneous control of molecular weight of polymer and microstructure of polymer in the polymerization of $\mathrm{Bd}$ with $\mathrm{Co}(\mathrm{acac})_{3} / \mathrm{MAO}$ catalyst was reported ${ }^{22)}$. Since high 1,4-cis poly $(\mathrm{Bd})$ was obtained in the polymerization of $\mathrm{Bd}$ with a $\mathbf{1 - M} / \mathrm{MAO}(\mathbf{M}=\mathrm{Ni}, \mathrm{Co})$ catalysts as mentioned above, the control of the molecular weight of poly(Bd) obtained with these catalysts was examined. The relationship between $M_{n}$ of the polymers and polymer yields are depicted in Figure 6. In the polymerization of $\mathrm{Bd}$ with 1-Ni/MAO catalyst, the molecular weights of the polymers did not change by reaction time, which is in a good agreement with that the polymerization of $\mathrm{Bd}$ with $\mathrm{Ni}(\mathrm{acac})_{2} / \mathrm{MAO}$ catalyst as reported in a previous paper ${ }^{23}$.

On the other hand, in the polymerization with 1$\mathrm{Co} / \mathrm{MAO}$, the molecular weights of the polymers increased with an increase of polymer yields, and the line passed through the origin. Moreover, the molecular weights of the polymers were in a good agreement with the values obtained assuming the catalyst efficiency is unity. These results indicate that the polymerization of $\mathrm{Bd}$ with 1Co/MAO has a living nature. Although, the molecular weight distribution $\left(M_{w} / M_{n}\right)$ is not narrow, but the values of $M_{w} / M_{n}$ kept almost constant at around 3 throughout reactions. This may be due to the slow initiation of the polymerization. In contrast to the polymerization of $\mathrm{Bd}$ with 1-Ni/MAO catalyst, the polymerization of Bd with 1Co complexes was found to be possible to control both the molecular weight of the poly(Bd) and 1,4-cis selectivity.

\section{Conclusion}

In the polymerization of $\mathrm{Bd}$ with metallosalen complexes in combination with MAO, 1-Co/MAO catalyst and 1-Ni/MAO catalysts showed high activities for the polymerization. High 1,4-cis polymer was obtained with the use of the catalysts, especially, 1-Co/MAO catalyst. The activity for the polymerization was influenced by substitution of the ligand of salen and mixing order of the reagents. The polymerization rate of $\mathrm{Bd}$ with 1-Co activated by $\mathrm{MAO}$ in the presence of $\mathrm{Bd}$ monomer was higher than that with simple metallosalen complexes, because of distortion of coplanarity between the central Co and the ligand of salen. The molecular weight control of the polymer is possible in the polymerization of $\mathrm{Bd}$ with $\mathbf{1 -}$ $\mathrm{Co} / \mathrm{MAO}$ catalyst.

\section{References}

1) Boor J. Jr.: "Ziegler-Natta Catalysts and Polymerizations" Academic Press, New York, (1979), Chap. 5.

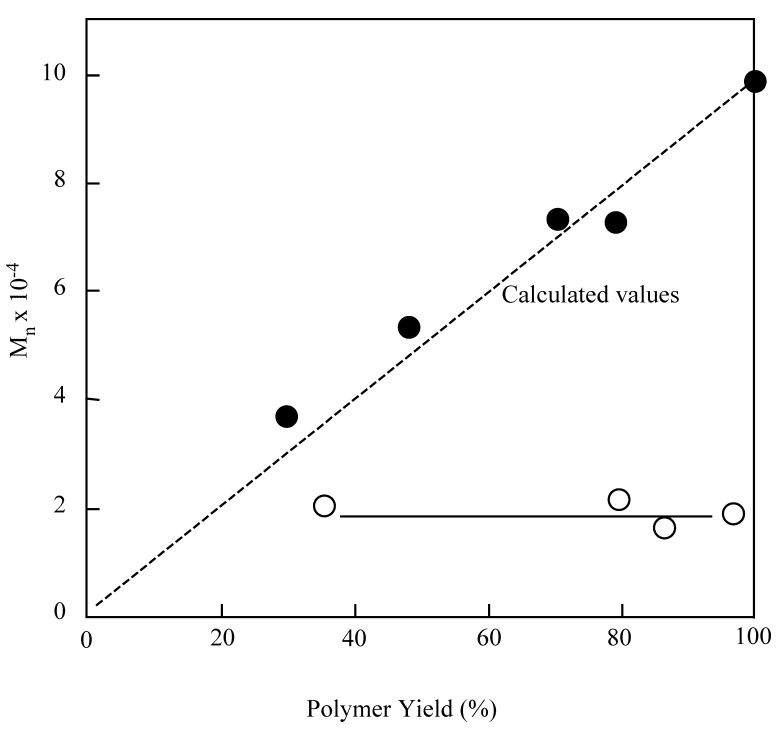

Figure 6. Relationship between polymer yield and $M_{n}$ for the polymerization of butadiene $(\mathrm{Bd})$ with metallosalen/MAO catalyst in $\mathrm{CH}_{2} \mathrm{Cl}_{2} \quad$ at $\quad 20^{\circ} \mathrm{C} ; \quad[\mathrm{Bd}]=1.2 \mathrm{~mol} / \mathrm{L}, \quad[\mathrm{Metal}]=6.7 \times 10^{-4} \mathrm{~mol} / \mathrm{L}$, $\mathrm{MAO} / \mathrm{Metal}=500 \mathrm{~mole}$ ratio, $(\bullet) \mathbf{1 - C o},(\bigcirc)$ 1-Ni. The reagents were charged in the order of metal complex, Bd, and MAO.

2) Kaminsky W., Arndt M.: Adv. Polym. Sci., 127, 143 (1996).

3) Johnson L. K., Killian C. M., Brookhart M.: J. Am. Chem. Soc., 117, 6414 (1995).

4) Johnson L. K., Mecking S., Brookhart M.: J. Am. Chem. Soc., 118, 267 (1996).

5) Scollard J. D., McConville D. H.: J. Am. Chem. Soc., 118, 10008 (1996).

6) Small B. L., Brookhart M., Bennet M. A.: J. Am. Chem. Soc., 120, 4049 (1998).

7) Britvsek G. J. P., Gibson V. C., Kimberley B. S., Maddox J., McTavish S. J., Solan G. A., White A. P., Williams D. J.: Chem. Commun., 849 (1998).

8) Saltman W. M.: Ind. Eng. Chem. Prod. Res. Dev., 3, 199 (1964).

9) Gippin M.: Ind.Eng. Chem. Prod. Res. Dev., 1, 32 (1962).

10) Dawans F., Teyssie Ph.: J. Polym. Sci. Polym. Lett., 7, 111 (1969).

11) Oehme A., Gebauer U., Gehrke K., Lechner M. D.: Angew. Makromol. Chem., 235, 121 (1996).

12) Oliva L., Longo P., Grassi A., Ammendola P., Pellecchia C.: Makromol. Chem. Rapid Commun., 11, 519 (1990).

13) Ricci G., Panagia A., Porri L.: Polymer, 37, 363 (1996).

14) Katsuki T.: Curr. Org. Chem., 5, 663 (2001).

15) Wang M., Zhu H. J., Jin K.: J. Catal., 220, 392 (2003).

16) Borker S., Saxena P.K.: Polym. Bull., 44, 167 (2000).

17) Ban H., Kase T., Murata M.: J. Polym. Sci. A, 39, 3733 (2001).

18) Kwag G., Jang Y., Lee H.: Polym. J., 31, 1274 (1999).

19) Endo K., Yamanaka Y.: Macromol. Chem. Phys., 202, 201 (2001).

20) Endo K., Hatakeyama N.: J. Polym. Sci. A, 39, 2798 (2001).

21) Endo K.: Nippon Gomи Kyoukaisi, 59, 309 (2002).

22) Endo K., Hatakeyama N.: Kobunnsi Ronbunsyu, 70, 69 (1997).

23) Endo K., Uchida Y., Matsuda Y.: Macromol. Chem. Phys., 197, 3515 (1996). 